\title{
Dual-band Dipole Antenna for 2.45 GHz and 5.8 GHz RFID Tag Application
}

\author{
Yanzhong Yu, Jizhen Ni, Zhixiang Xu \\ ${ }^{1}$ College of Physics \& Information Engineering, Quanzhou Normal University, Fujian, China \\ ${ }^{2}$ Key Laboratory of Information Functional Materials for Fujian Higher Education, Fujian, China \\ *corresponding author, E-mail: yuyanzhong0 59368 @ gmail . com
}

\begin{abstract}
In this paper, a dual-band dipole antenna for passive radio frequency identification (RFID) tag application at $2.45 \mathrm{GHz}$ and $5.8 \mathrm{GHz}$ is designed and optimized using HFSS 13. The proposed antenna is composed of a bent microstrip patch and a coupled rectangular microstrip patch. The optimal results of this antenna are obtained by sweeping antenna parameters. Its return losses reach to $-18.7732 \mathrm{~dB}$ and $-18.2514 \mathrm{~dB}$ at $2.45 \mathrm{GHz}$ and $5.8 \mathrm{GHz}$, respectively. The bandwidths (Return loss $<=-10 \mathrm{~dB}$ ) are $2.42 \sim 2.50 \mathrm{GHz}$ and 5.77 5.82 GHz. And the relative bandwidths are 3.3\% and $0.9 \%$. It shows good impedance, gain, and radiation characteristics for both bands of interest. Besides, the input impedance of the proposed antenna may be tuned flexibly to conjugate-match to that of the IC chip.
\end{abstract}

\section{Introduction}

In the last few years, the wireless identification and communications technology has been developing rapidly [1]. Radio frequency identification (RFID) is obtaining a growing interest to wirelessly track and identify objects due to its cheapness and reliability [2-4]. Now RFID finds many applications in lots of areas like pallet tracking, electronic toll collection, parking lot access, information industry, medical and defense [5-7]. Generally speaking, in RFID system different frequency spectrums are allocated to different countries or regions. For instance, 840.5 844.5 $\mathrm{MHz}$ and $920.5 \sim 924.5 \mathrm{MHz}$ in China, $865 \sim 867 \mathrm{MHz}$ in India, 902 928 MHz in Argentina and America, 866 869 $\mathrm{MHz}$ and 920 925 MHz in Singapore, and 952 955 MHz in Japan, and so on $[6,7]$. With the fast development of global economy, the exchanges of products made from different countries have become more and more frequent. In order to make the tag attached to the products effective, the RFID system should operate in dual-band or multi-band regime [8, 9]. An RFID system consists of a transponder (tag), which stores an identification code, and of a detector (reader) that is capable to retrieve the identity of the tags through a wireless wave. The passive RFID tag usually is composed of a tag antenna and an IC chip [1, 2]. Tag antenna is a key part of RFID systems. Therefore, a design of dual-frequency or multi-frequency tag antenna is of great importance for RFID application in different countries. In the current paper, a novel dual-frequency tag antenna, i.e.,
$2.45 \mathrm{GHz}$ and $5.8 \mathrm{GHz}$, is presented. It is composed of a bent microstrip patch and a rectangular microstrip patch. The rest of the present paper is organized as follows. Antenna design is described in Section 2. Section 3 presents the analysis and optimization results of the designed antenna. We give a brief conclusion in the last Section 4.

\section{Antenna Configuration}

The configuration of the proposed dual-band dipole antenna is illustrated in Fig. 1. This antenna works at $2.45 \mathrm{GHz}$ and $5.8 \mathrm{GHz}$ for RFID tag application. The basic structure of the designed antenna is composed of a bent and a rectangular microstrip patch. The common material FR4_epoxy, with relative dielectric constant $\varepsilon_{r}=4.4$, loss tangent $\tan \delta=0.017$ and thickness $h=0.5 \mathrm{~mm}$, is considered as substrate. The IC chip is connected to the bent microstrip patch, and the power exchanges between the bent and rectangular patch by coupling through the gap with length of $a$ and width of $e$. The initial sizes of the proposed antenna are given as follows: the length and width of the rectangular microstrip is $a=33 \mathrm{~mm}$ and $g=2 \mathrm{~mm}$; the length and width of the bent microstrip patch is $b=8 \mathrm{~mm}$ and $c=1 \mathrm{~mm}$, respectively; the space of $d=4 \mathrm{~mm}$, and the gap width of $e=1 \mathrm{~mm}$.

The proposed antenna is analyzed and optimized by using Ansoft simulation software High Frequency Structure Simulator (HFSS) [10]. This work is given in Section 3.

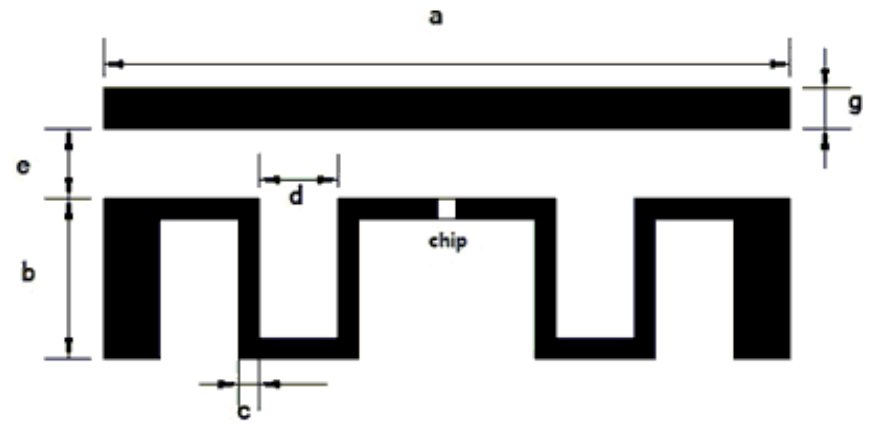

Fig. 1. Configuration of dual-band tag antenna

\section{Analysis and Optimization}

HFSS is an interactive software package for calculating the electromagnetic behavior of a structure. It is a famous electromagnetic simulation tool used for antenna design, and 
the design of complex RF electronic circuit elements including filters, transmission lines, and packaging. In the present paper, the HFSS is thus employed to analyze and optimize the proposed antenna. Fig. 2 shows the return loss S11 of the initial antenna as a function of frequency. It can be seen clearly from Fig. 2 that the initial antenna has two resonating frequency points within $1 \sim 7 \mathrm{GHz}$, the first one at $2.39 \mathrm{GHz}(\mathrm{S} 11=-10.6107 \mathrm{~dB})$ and the second at $5.86 \mathrm{GHz}$ $(\mathrm{S} 11=-33.6484 \mathrm{~dB})$. Neither of them is located at the expectation frequency points of $2.45 \mathrm{GHz}$ and $5.8 \mathrm{GHz}$. The relative bandwidths $(\mathrm{S} 11<=-10 \mathrm{~dB})$ of the first and second resonating frequencies are $(2.40-2.39) / 2.39=0.42 \%$ and $(5.88-5.84) / 5.86=0.68 \%$, respectively. Obviously, they do not satisfy the requirements of RFID applications.

Proper impedance matching must be considered in antenna design. Common antenna is usually connected to coaxial cable with impedance of $50 \Omega$ or $75 \Omega$. Consequently the value of input impedance of common antenna is adjusted to $50 \Omega$ or $75 \Omega$. However in RFID system the tag antenna is linked to the IC chip whose input impedance may be an arbitrary value [11] and is thus no longer $50 \Omega$ or $75 \Omega$. In order to achieve the purpose of maximum power transmission and improvement tag performance, proper impedance matching between the tag antenna and the IC chip is of considerable importance in RFID applications. Because the design and manufacturing of new IC chip is a big and costly venture, the input impedance of tag antenna is tuned to conjugate match to a specific IC chip available in the market [6]. The IC chip is usually a capacitive element and its input impedance is a complex value. We suppose that the input impedance of IC chip is $Z_{\text {chip }}=(25-j 136) \Omega$ in our work. The value of tag antenna impedance is a function of frequency, as depicted in Fig. 3. One can observe that the values of input impedances are $Z_{1}=(15.4+j 160.7) \Omega$ at $2.45 \mathrm{GHz}$ and $\mathrm{Z}_{2}=(20.8+\mathrm{j} 103.3) \Omega$ at $5.8 \mathrm{GHz}$. The purpose of conjugate matching between tag antenna and the IC chip do not achieve obviously. Accordingly, it can be found from Figs. 2 and 3 that both resonating frequency points and input impedances do not meet the design requirements yet. Therefore, the initial sizes of tag antenna must be optimized. Next, the effects of antenna sizes on their performances are analyzed.

In order to optimize the performances of initial antenna, the relevant parameters, like rectangular microstrip patch length $a$ and width $g$, bent microstrip patch length $b$ and space $d$, and the gap width $e$, are examined. Firstly, to investigate the influence of rectangular microstrip patch length $a$ on antenna performances, one can assume that others parameters of initial antenna remain unchanged and parameter $a$ varies from $30 \mathrm{~mm}$ to $36 \mathrm{~mm}$ only. Fig. 4 displays the return loss $\mathrm{S} 11$ as a function of frequency. It can be observed that within $1 \sim 7 \mathrm{GHz}$ the larger the length $a$ is, the lower are two harmonic frequencies. The effect of length $a$ on antenna input impedance is depicted in Fig. 5. It can be found that at $2.45 \mathrm{GHz}$, the value of resistance increases from $13 \Omega$ to $26 \Omega$ and the reactance adds from 64 $\Omega$ to $237 \Omega$; and at $5.8 \mathrm{GHz}$, the resistance varies from $16 \Omega$ to $20 \Omega$ and the reactance changes from $16 \Omega$ to $154 \Omega$, when length $a$ varies from $30 \mathrm{~mm}$ to $60 \mathrm{~mm}$. Therefore, a conclusion can be drawn that the values of resistance and reactance rise with the increase of length $a$ and grow faster and faster.

Secondly, the effect of width $g$ on antenna performances is investigated, as illustrated in Figs. 6 and 7. One may find that the return loss $\mathrm{S} 11$ within $1 \sim 7 \mathrm{GHz}$ and input impedance remain unchanged nearly when the value of width $g$ varies from $1 \mathrm{~mm}$ to $3 \mathrm{~mm}$.

Now, let us examine the effect of bent microstrip patch length $b$ on resonant frequency and input impedance, as shown in Figs. 8 and 9, respectively. One can observe from Fig. 8 that the harmonic frequency decreases with length $b$ increasing. We can also find from Fig. 9 that not only at $2.45 \mathrm{GHz}$ but also at $5.8 \mathrm{GHz}$ the values of resistance and reactance increase as the length $b$ increases.

Figs. 10 and 11 show the influence of bent microstrip patch space $d$ on return loss and input impedance. Within $1 \sim 7 \mathrm{GHz}$ the resonant frequency decreases with the increase of space $d$. Moreover, the change quantity of the second resonant frequency is larger than that of the first one. At $2.45 \mathrm{GHz}$, the real and imaginary parts of input impedance increase slowly as space $d$ raise from $2 \mathrm{~mm}$ to $3 \mathrm{~mm}$; but they also decrease slowly when the value of space $d$ increases from $3 \mathrm{~mm}$ to $4 \mathrm{~mm}$. Similarly, at $5.8 \mathrm{GHz}$ the real component of input impedance is almost unvaried, and the imaginary component increases from $-31 \Omega$ to $86 \Omega$ when space $d$ varies from $2 \mathrm{~mm}$ to $4 \mathrm{~mm}$.

Lastly, the influence of gap width $e$ is analyzed as depicted in Figs. 12 and 13. Within $1 \sim 7 \mathrm{GHz}$ the first harmonic frequency rises but the second does not change almost while the gap width $e$ increases from $0.5 \mathrm{~mm}$ to 1.5 $\mathrm{mm}$. At $2.45 \mathrm{GHz}$, the imaginary part of input impedance reduces from $250 \Omega$ to $122 \Omega$ but the real part remains unchanged when increasing the space $d$ from $0.5 \mathrm{~mm}$ to $1.5 \mathrm{~mm}$. And the change of input impedance at $5.8 \mathrm{GHz}$ is very small.

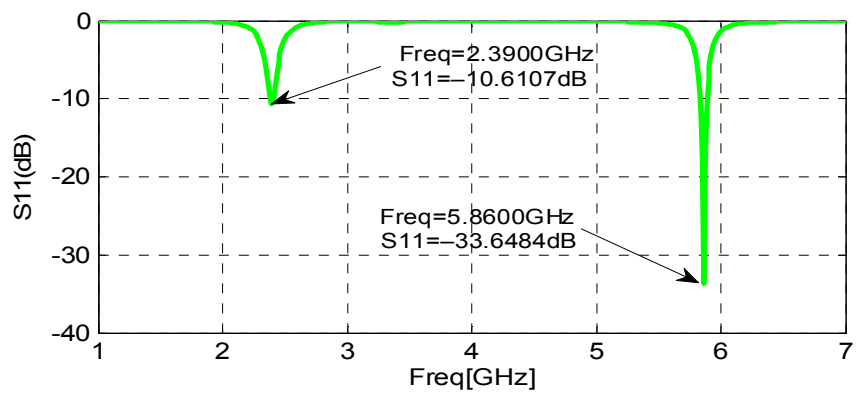

Fig. 2. Return loss $\mathrm{S} 11$ of initial antenna

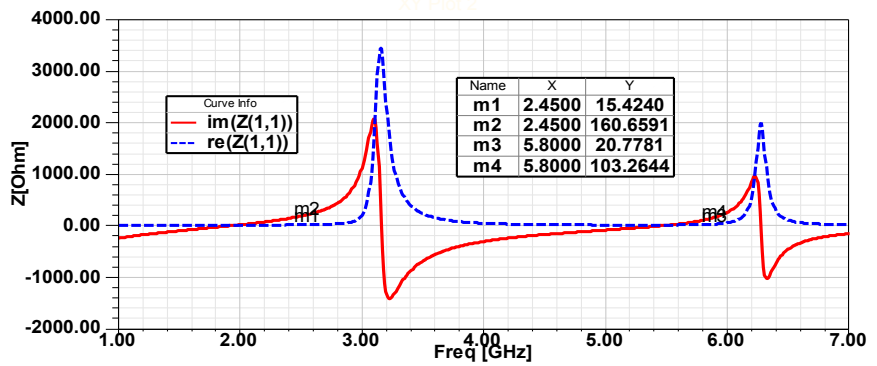

Fig. 3. Input impedance of initial antenna 


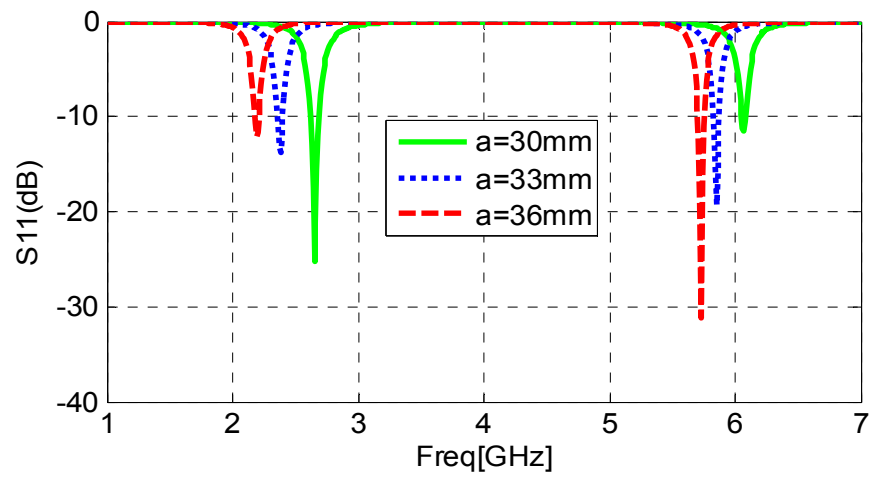

Fig. 4. Influence of length $a$ on resonating frequency

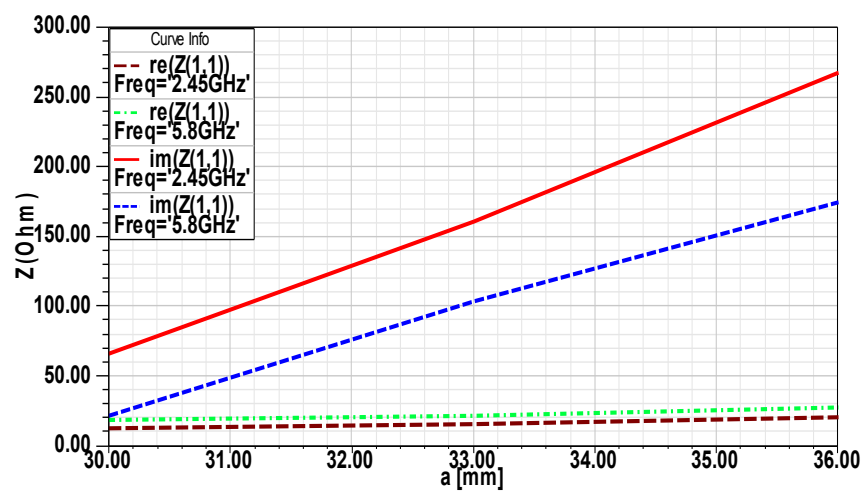

Fig. 5. Effect of length $a$ on input impedance

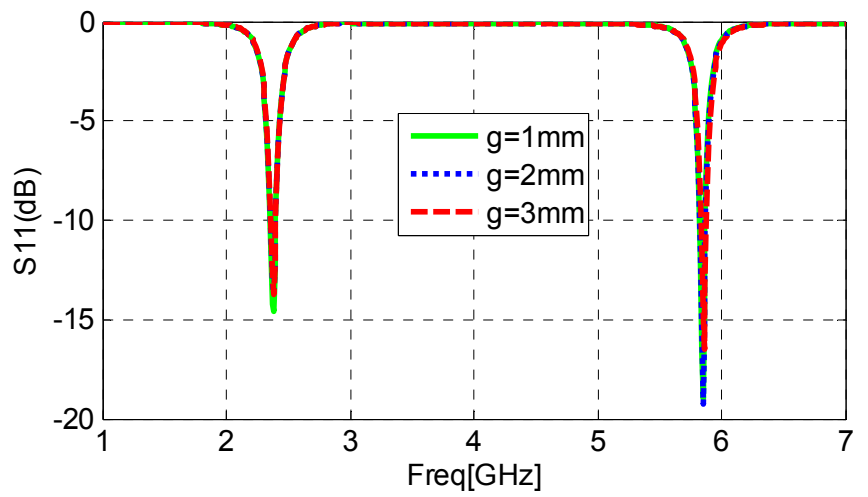

Fig. 6. Return loss S11 with different width $g$

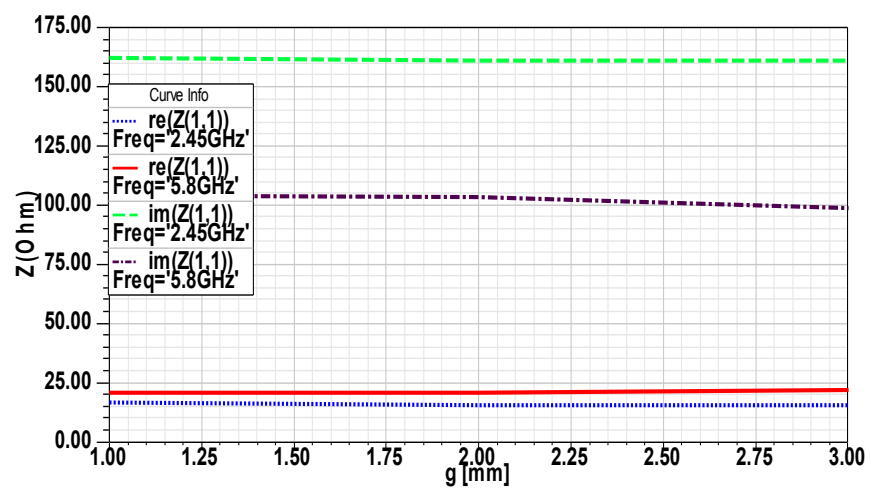

Fig. 7. Input impedance with different width $g$

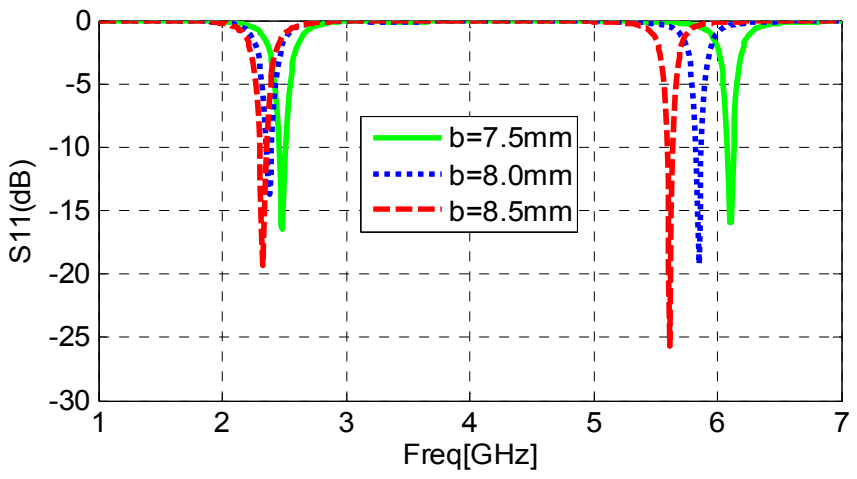

Fig. 8 Influence of length $b$ on resonating frequency

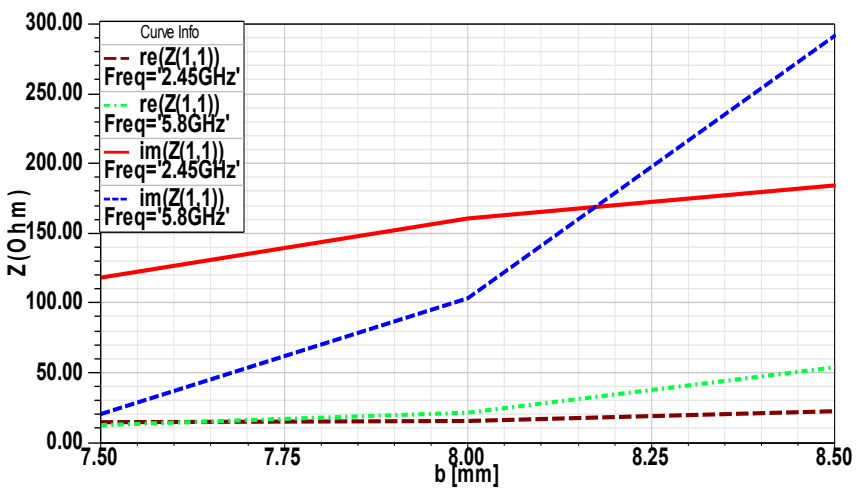

Fig. 9. Effect of length $b$ on input impedance

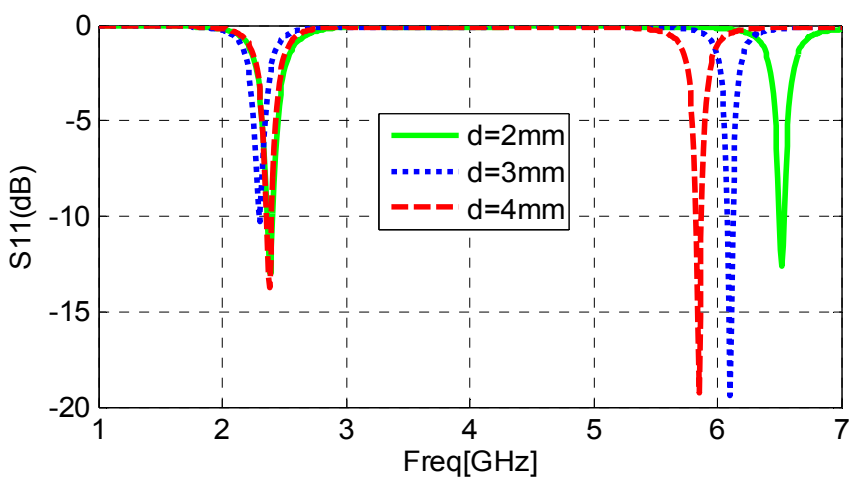

Fig. 10 Influence of space $d$ on resonating frequency

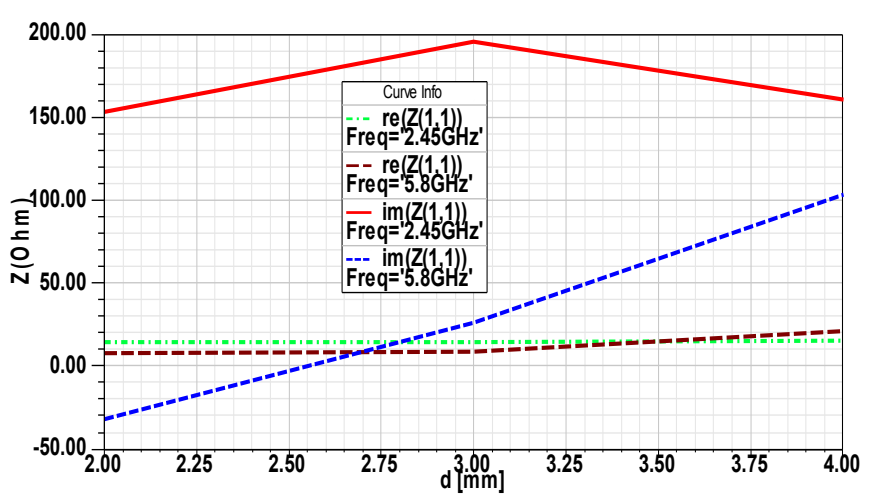

Fig. 11. Effect of space $d$ on input impedance 


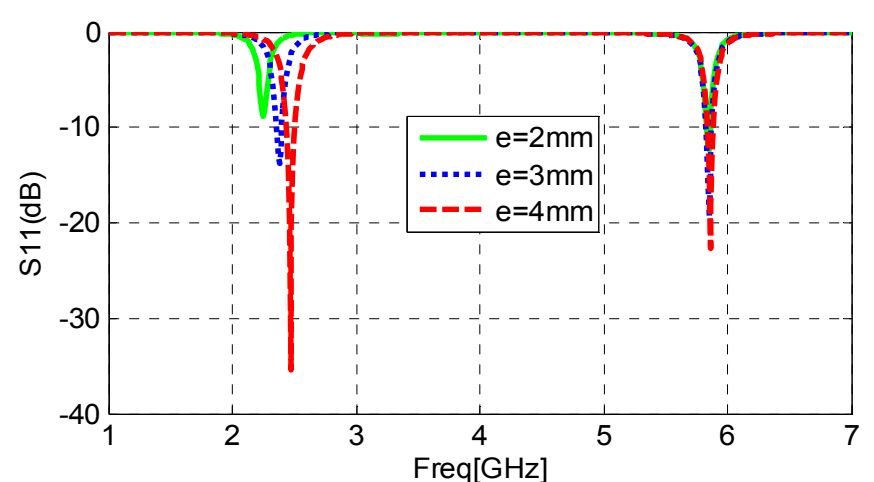

Fig. 12 Influence of gap width $e$ on resonating frequency

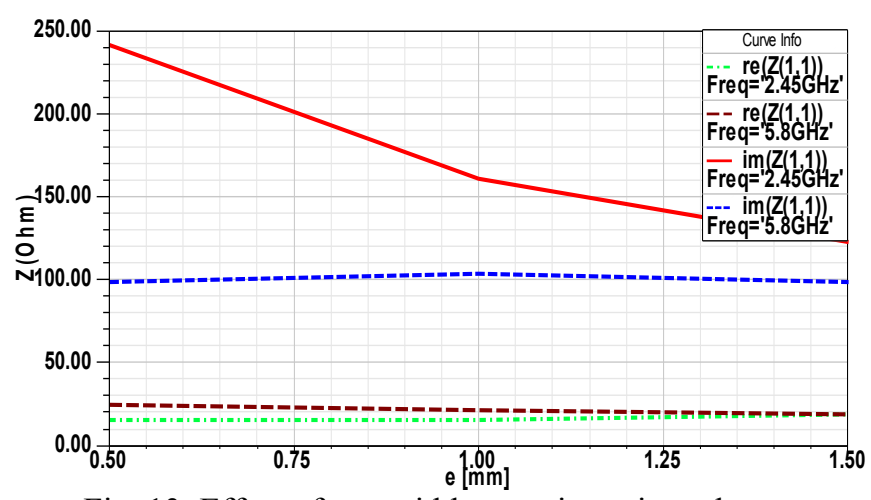

Fig. 13. Effect of gap width $e$ on input impedance

On the basis of analysis above, we find that the gap width $e$ only affects on the first resonating frequency. We thus can drop the second resonating frequency point to 5.8 $\mathrm{GHz}$ by increasing the rectangular microstrip length $a$. Then the first resonating frequency can be tuned to 2.45 $\mathrm{GHz}$ by changing the value of gap width $e$. In a word, by optimizing the sizes of initial antenna repeatedly, the optimal dimensions of the proposed tag antenna are obtained at last. They are as follows: $a=34.7 \mathrm{~mm}$, $b=8 \mathrm{~mm}, c=1 \mathrm{~mm}, d=4 \mathrm{~mm}, e=3.5 \mathrm{~mm}, g=2 \mathrm{~mm}$, $h=0.5 \mathrm{~mm}$.

The return loss S11 as a function of frequency for the optimized tag antenna is illustrated in Fig. 14. It can be seen clearly that at the range of $1 \sim 7 \mathrm{GHz}$ the antenna has two resonating frequency points, one at $2.45 \mathrm{GHz}$ (S11=$18.7732 \mathrm{~dB})$ and the other at $5.8 \mathrm{GHz}(\mathrm{S} 11=-18.2514 \mathrm{~dB})$. For the first resonating frequency of $2.45 \mathrm{GHz}$, the absolute bandwidth $(\mathrm{S} 11<=-10 \mathrm{~dB})$ reaches to $80 \mathrm{MHz}(2.42 \sim 2.50$ $\mathrm{GHz})$ and the fractional bandwidth is $(2.50-$ $2.42) / 2.45=3.3 \%$. For $5.8 \mathrm{GHz}$, the absolute and fractional bandwidths are $50 \mathrm{MHz}$ and $0.9 \%$ respectively.

Fig. 15 presents the input impedance of the optimized tag antenna. It can be observed from Fig. 15 that the values of input impedance are $\mathrm{Z}_{1}=(30.8+\mathrm{j} 132.1) \Omega$ at $2.45 \mathrm{GHz}$ and $Z_{2}=(20.2+j 140.2) \Omega$ at $5.8 \mathrm{GHz}$. Both are close to the conjugate value of $Z_{\text {chip }}=(25-j 136) \Omega$, which is an assumed value of input impedance of the IC chip. This mean it has a good conjugate match between the IC chip and tag antenna. Generally, the resistance of most of RFID IC chips varies from $10 \Omega$ to $30 \Omega$, and the reactance limits in the range of (100 300) $\Omega$. Therefore, the purpose of conjugate matching can be achieved only by tuning the parameter $a$ or $b$. This may meet the impedance matching requirement of most of RFID IC chips.

Antenna gain is an important index to measure antenna electric performance. The larger the total gain is, the farther the read range of RFID system become. The 3D gain patterns of the optimized tag antenna at $2.45 \mathrm{GHz}$ and 5.8 $\mathrm{GHz}$ are displayed in Figs. 16 and 17, respectively. The values of maximum gain are $2.68 \mathrm{dBi}$ at $2.45 \mathrm{GHz}$ and 3.27 $\mathrm{dBi}$ at $5.8 \mathrm{GHz}$. These performance indexes meet the requirements of RFID applications. In order to observe the pattern more clearly, Fig. 18 illustrates the 2D radiation patterns in xz-plane $\left(\mathrm{phi}=0^{\circ}\right)$ and yz-plane $\left(\mathrm{phi}=90^{\circ}\right)$ at $2.45 \mathrm{GHz}$. The radiation in xz-plane is maximum and omnidirectional, and yet in yz-plane is a poor directionality. The similar chart for $5.8 \mathrm{GHz}$ is shown in Fig. 19. It can be seen from Fig. 19 that in xz-plane the radiation exhibits an approximation to omnidirectional pattern, but in yz-plane the sidelobe appears at $\theta=0^{\circ}$ or $\theta=180^{\circ}$.

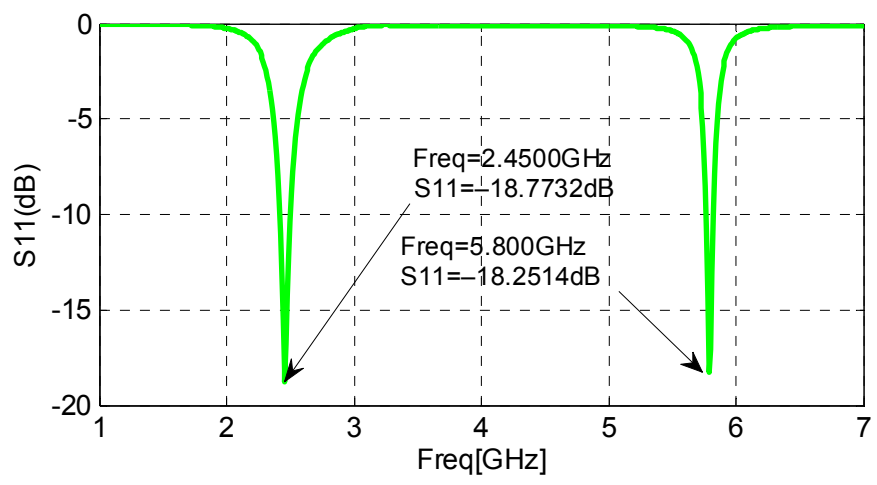

Fig. 14. Return loss of optimized tag antenna

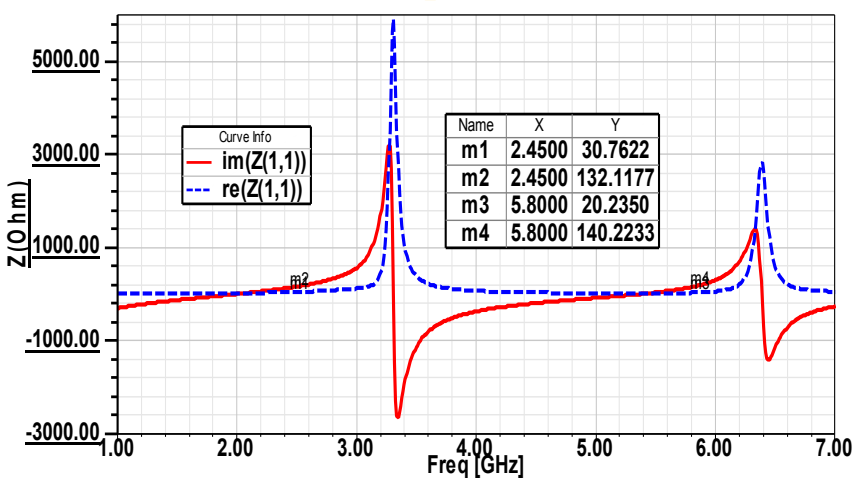

Fig. 15. Input impedance of optimized tag antenna

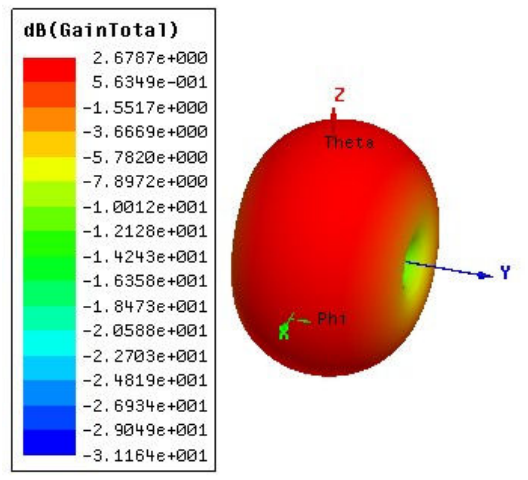

Fig. 16. 3D gain pattern at $2.45 \mathrm{GHz}$ 


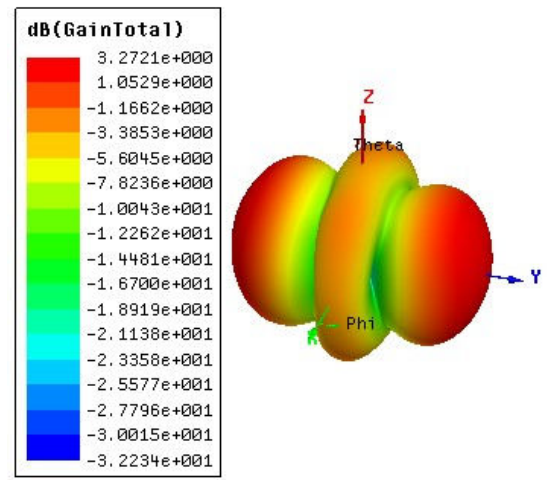

Fig. 17 3D gain pattern at $5.8 \mathrm{GHz}$

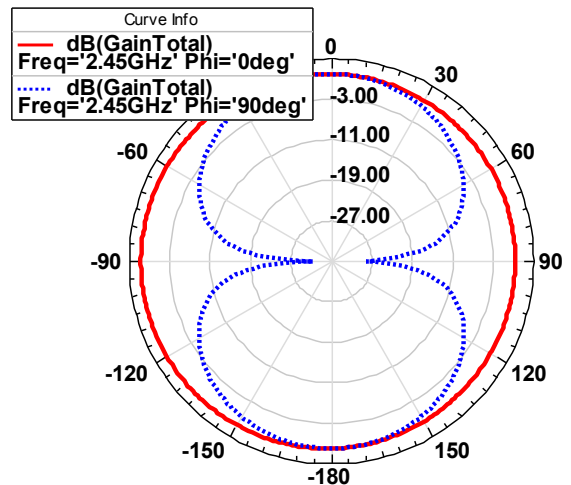

Fig. 18. 2D radiation patterns at $2.45 \mathrm{GHz}$

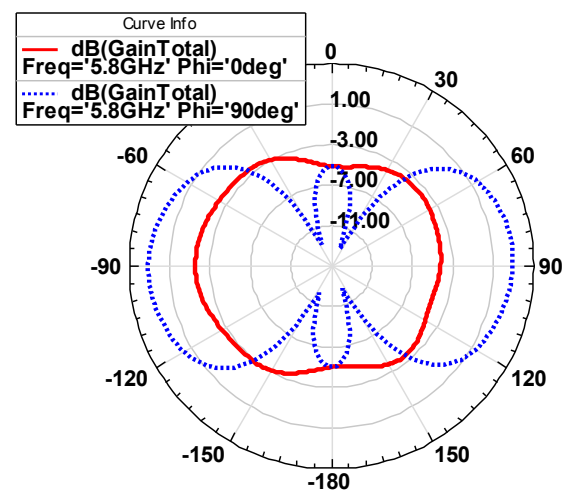

Fig. 19. 2D radiation patterns at $5.8 \mathrm{GHz}$

\section{Conclusions}

With the rapid development of RFID technology and applications, the operating frequency of tag antenna has been developing to microwave wavebands $(2.45 \mathrm{GHz}$, $5.8 \mathrm{GHz}$ ). The design of tag antenna at these wavebands has become more and more important. In the present paper, the tag antenna with dual-band work frequency, i.e. $2.45 \mathrm{GHz}$ and $5.8 \mathrm{GHz}$, is proposed. Its performances are analyzed and optimized by using the HFSS. The simulation results demonstrate the designed tag antenna satisfy the application requirements of RFID system. It can find applications in traffic or logistics management.

\section{Acknowledgements}

This work was supported by the Key Project of Science and Technology Department of Fujian Province (No. 2012H0035), the Key Project of Quanzhou City Science and Technology Program (No. 2011G14), and the Key Discipline of Electronic Science and Technology.

\section{References}

[1] A. Ali Babar, T. Björninen, V.A. Bhagavati, L. Sydänheimo, P. Kallio, and L. Ukkonen. Small and Flexible Metal Mountable Passive UHF RFID Tag on High-Dielectric Polymer-Ceramic Composite Substrate. IEEE Antennas Wirel. Propag. Lett. Vol. 11, pp. 13191322, 2012.

[2] E. Digiampaolo, F. Martinelli. Mobile robot localization using the phase of passive UHF RFID signals. IEEE Trans. Ind. Electron. Vol. 6, No. 1, pp. 365-376, Jan. 2014.

[3] S. M. Hu, Y. Zhou, C. L. Law, and W. B. Dou. Study of a Uniplanar Monopole Antenna for Passive Chipless UWB-RFID Localization System. IEEE Trans. Antennas Propag., Vol. 58, pp. 271-278, 2010.

[4] H. T. Chou, T. M. Hung, N. N. Wang, et.al. Design of a near-field focused reflect array antenna for $2.4 \mathrm{GHz}$ RFID reader applications. IEEE Trans. on Antennas and Propag., Vol. 59, pp. 1013-1018, 2011.

[5] S. Jeon, Y. Yu and J. Choi. Dual-band slot-coupled dipole antenna for $900 \mathrm{MHz}$ and $2.45 \mathrm{GHz}$ RFID tag application. Electronics Letters, Vol. 42, No. 22, Oct. 2006.

[6] K.V. S. Rao, P. V. Nikitin, and S. F. Sander. Antenna design for UHF RFID tags: a review and a practical application. IEEE Trans. Antennas Propag., Vol. 53, No. 12, pp. 3870-876, Dec. 2005.

[7] Raviteja, Chinnambeti; Varadhan, Chitra; Kanagasabai, Malathi; Sarma, Aswathy K.; Velan, Sangeetha. A fractal-based circularly polarized UHF RFID reader antenna. IEEE Antennas Wirel. Propag. Lett., Vol. 13, pp. 499-502, 2014.

[8] Dongho Kim, and Junho Yeo, Dual-Band Long-Range Passive RFID Tag Antenna Using an AMC Ground Plane Digiampaolo, F. Martinelli. IEEE Trans. Antennas Propag., Vol. 60, No. 6, pp. 2620-2626, June 2012.

[9] C. Varadhan, J. K. Pakkathillam, M. Kanagasabai, R. Sivasamy, R. Natarajan, and S. K. Palaniswamy. Triband Antenna Structures for RFID Systems Deploying Fractal Geometry. IEEE Antennas Wirel. Propag. Lett., Vol. 12, pp. 437-440, 2013.

[10]Ansoft High Frequency Structure Simulator (HFSS), Ver. 13.0, Ansoft Corporation.

[11]B. Yang, Q. Y. Feng. A folded dipole antenna for RFID tag. Int. Conf. Microw. Millimeter Wave Technol. Proc. 2008, pp. 1047-1049, Nanjing, China. 